\title{
CAUSES OF LOWER LIMB AMPUTATION IN PATIENTS REGISTERED AT PAKISTAN INSTITUTE OF PROSTHETIC AND ORTHOTIC SCIENCES PESHAWAR-PAKISTAN
}

\section{Aziz Ahmad ${ }^{1 \otimes}$, Omar Ashfaq², Nizar Akhtar ${ }^{3}$, Tabassum Rana ${ }^{3}$, Momi Gul ${ }^{3}$}

\begin{abstract}
OBJECTIVE: To find out the main causes of lower limb amputation (LLA) during the four years period at Pakistan Institute of Prosthetic and Orthotic Sciences (PIPOS) Rehabilitation Services Programme (PRSP) Peshawar, Khyber Pakhtunkhwa, Pakistan.

METHODS: This retrospective cross-sectional study evaluated four-year records of the registered LLA patients from PRSP Peshawar for assessment and evaluation from January 2010 to December 20I3. The collected data was analyzed using Microsoft Excel, descriptive analysis like means, standard deviation, percentages, range etc, on the bases of age, gender and causes of amputation were calculated.

RESULTS: Out of 5820 patient with LLA registered during the study period, 5 I $16(87.9 \%)$ were males and 704 (I $2.1 \%)$ were females. Mean age of patients was $37 \pm 19$ years and about $67.6 \%(n=3933)$ patients were $\leq 40$ years of age. Overall, trans-tibial amputations were common $(n=3582 / 5820 ; 61.6 \%)$, followed by trans-femoral amputation ( $n=1496 ; 25.7 \%)$. Generally, an increasing trend in frequency of patients with LLA was observed over four years. Major causes of LLA were trauma (6I.9\%), reconstructive surgeries (I5.4\%), various diseases (8.2\%) and congenital (2.1\%). In I $2.4 \%$ cases, cause of LLA was not documented. Bomb blast injuries (21.6\%) and road traffic accidents (14.6\%) were main traumatic causes of LLA and diabetes mellitus $(4.6 \%)$ was the commonest disease-related cause of LLA.
\end{abstract}

CONCLUSION: Majority of patients were males and were $\leq 40$ years of age. Trans-tibial amputations were common. Trauma (mainly bomb blasts injuries and road traffic accidents), reconstructive surgeries and various diseases like diabetes are the leading causes of LLA in patients at PRSP, Peshawar, Pakistan.

KEY WORDS: Amputation (MeSH); Amputation, Traumatic (MeSH); Lower limb amputation (Non-MeSH); Hip disarticulation (Non-MeSH); Trans femoral amputation (Non-MeSH); Knee disarticulation (Non-MeSH); Trans tibial amputation (Non-MeSH); Partial foot amputation (Non-MeSH); Accidents, Traffic (MeSH); Amputation, Congenital (MeSH).

THIS ARTICLE MAY BE CITED AS: Ahmad A, Ashfaq O, Akhtar N, Rana T, Gul M. Causes of lower limb amputation in patients registered at Pakistan Institute of Prosthetic and Orthotic Sciences Peshawar-Pakistan. Khyber Med Univ J 20I 9; I I (I):4 I-4. DOI: I0.35845/kmuj.20I9.18096.

\section{INTRODUCTION}

$\mathrm{A}^{\mathrm{n}}$ mputations are performed for variety of reasons including trauma, diseases, tumors, infections and congenital malformations, with the aim to save the life of an individual.' Limb loss is one of the most physically and psychologically devastating event, not only causes major disfigurement but it also affect mobility, independence and quality of life." "Major" lower limb loss is
I Assistant Professor, Pakistan Institute of Prosthetic and Orthotic Sciences (PIPOS), Peshawar, Pakistan Email冈: azizamgee@gmail.com

2 Trainee PIPOS, Peshawar, Pakistan

3 Assistant Professor, PIPOS, Peshawar, Pakistan

Date Submitted: January 02, 2018

Date Revised: $\quad$ March 01, 2019

Date Accepted: March 06, 2019

defined as amputation above the knee, below the knee or the foot amputation. Causes of lower limb amputations varies from country to country and also varies among developing and developed countries. ${ }^{3}$ It is very difficult to determine the exact global burden of limb amputation due to poor record keeping in many countries. ${ }^{4}$ In USA, 1.6 million people were living with an amputated limb in 2005 and this figure is expected to rise to 3.6 million in $2050 .^{5}$

Pakistan is a country facing lot of health related issues due to war on terror and natural calamities like earthquake and floods over the last two decades. However, due to non-availability of robust epidemiological data, disease burden of lower limb amputation (LLA) cannot be established. Only a few studies on LLA have been conducted in civil and military hospitals of Pakistan. ${ }^{6,7}$ Khyber Pakhtunkhwa (KP) province and Federally Administered Tribal Areas (FATA) are the main affected areas of war against terror and other natural calamities like floods and earthquake. However, there is no study available on demographics of LLA. Therefore, this study was planned to study the main causes of LLA at Pakistan Institute of Prosthetic and Orthotic Sciences (PIPOS) Rehabilitation Services Programme (PRSP) Peshawar, Khyber Pakhtunkhwa, Pakistan. PRSP was established in 2007 and provides rehabilitation services throughout Pakistan and particularly to Khyber Pakhtunkhwa and tribal areas.

\section{METHODS}

This retrospective study was conducted at PIPOS Rehabilitation Services Programme, Peshawar, Khyber Pakhtunkhwa, Pakistan. Data was collected from the available record of 
TABLE I: AGE DISTRIBUTION AMONG REGISTERED PATIENTS (JANUARY 2010 - DECEMBER 20I3)

\begin{tabular}{|c|c|c|c|c|c|c|}
\hline \multirow[b]{2}{*}{ Year } & \multicolumn{5}{|c|}{ Age Groups (years) } & \multirow[b]{2}{*}{ Total } \\
\hline & $\begin{array}{l}01-10 \\
{[n(\%)]}\end{array}$ & $\begin{array}{l}\text { II - 20 } \\
\text { [n (\%)] }\end{array}$ & $\begin{array}{l}21-30 \\
{[n(\%)]}\end{array}$ & $\begin{array}{l}31-40 \\
{[n(\%)]}\end{array}$ & $\begin{array}{c}>40 \\
{[n(\%)]}\end{array}$ & \\
\hline 2010 & $42(3.64)$ & $179(|5.5|)$ & $294(25.48)$ & $209(18.11)$ & $430(37.26)$ & 1154 \\
\hline 2011 & $60(4.48)$ & $180(13.43)$ & $355(26.49)$ & $315(23.5 I)$ & $430(32.09)$ & 1340 \\
\hline 2012 & $71(4.32)$ & $286(I 7.4 I)$ & $425(25.87)$ & $323(19.66)$ & $538(32.74)$ & 1643 \\
\hline 2013 & $82(4.87)$ & $313(18.60)$ & $435(25.85)$ & $364(21.63)$ & $489(29.06)$ & 1683 \\
\hline Total & $255(4.38)$ & $958(16.46)$ & 1509 (25.93) & $12 I I(20.8 I)$ & I887 (32.42) & 5820 \\
\hline
\end{tabular}

TABLE II: TYPE OF LOWER LIMB AMPUTATION IN BOTH GENDERS AMONG REGISTERED PATIENTS

\begin{tabular}{|l|c|c|c|}
\hline \multicolumn{1}{|c|}{ Type } & Male [n (\%)] & Female [n (\%)] & Total [n (\%)] \\
\hline Hip Disarticulation & $2 \mathrm{I}(9 \mathrm{I} .3)$ & $2(8.7)$ & $23(0.2)$ \\
\hline Trans Femoral Amputation & $\mathrm{I} 329(88.8)$ & $\mathrm{I} 67(\mathrm{II} .2)$ & $\mathrm{I} 496(25.7)$ \\
\hline Knee Disarticulation & $332(87.6)$ & $47(\mathrm{I} 2.4)$ & $379(6.5)$ \\
\hline Trans Tibial Amputation & $3 \mathrm{I} 28(87.3)$ & $454(\mathrm{I} 2.7)$ & $3582(6 \mathrm{I} .6)$ \\
\hline Partial Foot Amputation & $306(90.0)$ & $34(10.0)$ & $340(5.9)$ \\
\hline \multicolumn{1}{|c|}{ Total } & $\mathbf{5 I ~ I 6 ( 8 7 . 9 )}$ & $\mathbf{7 0 4 ( \mathbf { I 2 . 1 } )}$ & $\mathbf{5 8 2 0}$ \\
\hline
\end{tabular}

TABLE III: CAUSES OF LOWER LIMB AMPUTATION AMONG REGISTERED PATIENTS

\begin{tabular}{|c|c|c|c|}
\hline \multicolumn{2}{|c|}{ Causes of Amputations } & $\begin{array}{l}\text { Frequency } \\
(n=5820)\end{array}$ & Percentage \\
\hline \multirow{8}{*}{$\begin{array}{l}\text { Traumatic } \\
(n=3603 / 5820 ; 61.9 \%)\end{array}$} & Bomb Blasts & 1259 & 21.6 \\
\hline & Road Traffic Accident & 847 & 14.6 \\
\hline & Firearm Injuries & 671 & 11.5 \\
\hline & Other War injuries & 497 & 8.5 \\
\hline & Land Mines & 139 & 2.4 \\
\hline & Work-related Trauma & 122 & 2.1 \\
\hline & Shelling & 40 & 0.7 \\
\hline & Burns & 28 & 0.5 \\
\hline \multirow{3}{*}{$\begin{array}{l}\text { Reconstructive Surgeries } \\
(\mathrm{n}=896 / 5820 ; 15.4 \%)\end{array}$} & Tibial Spur & 535 & 9.2 \\
\hline & Neuroma & 186 & 3.2 \\
\hline & Severe Contractures & 175 & 3.0 \\
\hline \multicolumn{2}{|c|}{ Cause Not Documented $(n=72 \mathrm{I} / 5820 ; 12.4 \%)$} & 721 & 12.4 \\
\hline \multirow{6}{*}{$\begin{array}{l}\text { Diseases } \\
(n=478 / 5820 ; 8.2 \%)\end{array}$} & Diabetes Mellitus & 267 & 4.6 \\
\hline & Deep Vein Thrombosis & 71 & 1.2 \\
\hline & Osteosarcoma & 48 & 0.8 \\
\hline & Carcinoma & 39 & 0.7 \\
\hline & Gangrene & 39 & 0.7 \\
\hline & Osteomyelitis & 14 & 0.2 \\
\hline \multicolumn{2}{|c|}{ Congenital $(n=122 / 5820 ; 2.1 \%)$} & 122 & 2.1 \\
\hline
\end{tabular}

patients registered at PRSP Peshawar from January 2010 to December 2013. The following information were collected on the data extraction form:

- Information about gender and age

- Information about level of amputation

- Information about cause of

\section{amputation}

The collected data was analyzed with the Microsoft excel (20I3) and descriptive statistical analysis was done, means, standard deviation (SD), percentages, range etc, on the bases of age, gender and cause of amputation were calculated. Sample included patients registered during the prescribed period at PRSP Peshawar mainly belonging to KP and FATA, both genders were included irrespective of the level of amputation, cost, creed, religion and age limit. Patients registered before January 2010 and after December 20 I3, those with upper limb amputations and with other disabilities were not included in the study.

\section{RESULTS}

Five thousand eight hundred and twenty patients with lower limb amputations were registered during the four years study period (January 2010 - December 20I3). The mean age was $37 \pm 19$ years with a range of 7 to 67 years. About $67.6 \%(n=3933)$ patients were $\leq 40$ years of age and $32.4 \%(n=1887)$ were in age group $>40$ years (Table I). Overall, $31.4 \%$ increase in patient's registration was found from 2010 to 2013 , the number of registered patients rose from II 54 in 2010 to I 683 in 2013.

About $87.9 \%$ of the registered patients were male and it remained very high at all levels of amputations in the lower limb. Overall, trans-tibial amputations were common ( $n=3582 / 5820 ; 61.6 \%)$, followed by trans-femoral amputation $(n=1496 ; 25.7 \%)$. Type of LLA and gender distribution is given in Table ll.

Major causes of LLA were trauma (61.9\%), reconstructive surgeries (I5.4\%), various diseases $(8.2 \%)$ and congenital (2.1\%). In $12.4 \%$ cases, cause of LLA was not documented (Table III).

Bomb blast injuries (21.6\%), road traffic accidents (14.6\%) and firearm injuries $(n=671 ; 11.5 \%)$ were the main traumatic causes of LLA. Neuroma contributing to 186 (3.2\%) cases was the major cause of LLA during reconstructive surgery. Diabetes mellitus $(4.6 \%)$ and deep vein thrombosis $(n=71 ; 1.2 \%)$ were the most common disease-related cause of LLA.

\section{DISCUSSION}

Over the four years period (January 2010 to December 20I3), an increase of $31.4 \%$ in patients registration was found for their rehabilitation with the 
provision of artificial limbs. More astonishingly the younger population (below the age of 40 years) was about $68 \%$ of the total number of registered patients. This is an eye opening for all health care providers and policy makers to provide better facilities and a long term planning for the rehabilitation, social reintegration and empowerment in the society.

Amputation caused due to trauma contributed to about $62 \%$ of the registered patients. Majority of LLA in the developing world are due to trauma-related causes. ${ }^{8,9}$ Pooja and Sangeeta reported trauma as a major cause $(70.3 \%)$ of amputation in India in all age groups. ${ }^{10}$ In Nepal, the amputations caused by trauma were as high as $86.58 \% .^{8}$ Similarly in Iran, traumatic amputations remained with highest figure (46\%). "In Pakistan, Masood J, et al. ${ }^{6}$ reported trauma $(45.3 \%)$ as a second leading cause of LLA in Civil Hospital of Karachi. While Rathore FA, et al. ${ }^{7}$ reported trauma in almost all (96.7\%) patients in military rehabilitation center. Findings of Rathore FA, et al, ${ }^{7}$ are plausible in military context where mine blast injury $(59.3 \%)$ and other causes like multiple shrapnels and rocket/missile related injuries were reported. In our study, higher proportion of bomb blasts injuries (21.6\%), firearm injuries (II.5\%), land mines (2.4\%) and other war injuries $(8.5 \%)$ reflected the impact of war on terror, the personal/intertribal enmities and across the border firing along the border with Afghanistan and India.

Road traffic accidents (RTA) in our study was the second most common (14.6\%) traumatic cause of LLA. Masood J, et al. ${ }^{6}$ have not reported any case of RTA in their study while Rathore FA, et al. ${ }^{7}$ had cases of RTA but not mentioned the exact figures. Singh G, et al. ${ }^{12}$ reported $21.79 \%$ cases of RTA in LLA in India. RTA was also the major contributor of traumatic amputation in Indian patients, as reported by Maqsood M, et al. ${ }^{13}$ In Nepal, RTA accounted for $74.29 \%$ cases of traumatic sub-groups of LLA. This shows the gravity of road safety issues in the South Asian region.

Reconstructive surgeries were performed in $15.4 \%$ cases, in our study, mainly for tibial spur, neuroma and severe contractures. These issues were not addressed in previous local studies. Issues of reconstructive surgeries, prosthesis and rehabilitation in amputations of limbs during the 2005 earthquake in Pakistan were highlighted by Awais SM, et al. ${ }^{14}$

Diabetes mellitus was on top among medical diseases requiring LLA, in our study, accounting for $4.6 \%$ cases. Masood J, et al. ${ }^{6}$ reported diabetes as the leading $(54.7 \%)$ cause of LLA in Pakistan. Humail SM, et al. ${ }^{15}$ reported diabetic foot as a major cause $(70.76 \%)$ of LLA in hospital-based study at Karachi. In Pakistani diabetic patients, foot ulcer is the major cause of LLA, which is preventable by good glycemic control and foot care. ${ }^{16}$ In $12.4 \%$ cases, cause of amputation was not documented and needs attention of the PIPOS administration for future record keeping.

Most common sites of LLA in our study were trans-tibial amputation (below knee amputation) in $61.6 \%$ cases and trans-femoral amputation (above knee amputation) in $25.7 \%$ cases. Rathore $\mathrm{FA}$, et al. ${ }^{7}$ had similar findings, reported trans-tibial amputation in $65 \%$ cases and trans-femoral amputation in $30 \%$ cases. To save the natural knee joint is one of the key addition to the effective rehabilitation in terms of achieving smooth and efficient gait, natural knee function and less energy consumption after rehabilitation.

Another important finding of our study was that about $67.6 \%$ of our patients were $\leq 40$ years of age and mean age of patients was $37 \pm 19$ years. Rathore FA, et al. ${ }^{7}$ reported $86.2 \%$ patients between 20-40 years of age. Similar results were also reported from India ${ }^{10,12}$ and Iran." Gender distribution showed male predominance $(87.9 \%)$ in our study. Masood J, et al. ${ }^{6}$ reported $86.8 \%$ male patients and Rathore FA, et al, ${ }^{7}$ had $100 \%$ male patients. Other developing countries also reported male preponderance for LLA. ${ }^{9-12,17}$ Due to tribal background and Pathan culture, young males are more involved in personal enmity and are more prone to injuries and road traffic accidents compared to the female population, who are less likely to get out of homes.
Other contributing factors are direct and indirect effects of the 4 decades long Afghan war, war on terror and bomb blasts on the tribal belt and the province of Khyber Pakhtunkhwa.

\section{CONCLUSION}

Majority of patients were males and were $\leq 40$ years of age. Trans-tibial and trans-femoral amputations were common sites of amputations. Traumatic causes were predominant including bomb blasts injuries and road traffic accidents. Reconstructive surgeries and various diseases like diabetes are the other leading causes of LLA in patients at PRSP, Peshawar, Pakistan.

\section{RECOMMENDATIONS}

It was good to see that the surgeons prefer to save the natural knee joint by carrying out trans tibial amputations more often. However, further research at a greater scale (including data from all tertiary hospitals) is need to determine the exact nature of the amputations in the lower limb of both genders and the different years of age. Documentation and record keeping of the institutions needs improvement to fill the gap in data management.

Looking at the varying results in patients registered for rehabilitation at PIPOS/ PRSP, it is recommended to have a long term planning for the rehabilitation of these patients, which include a greater number of younger populations. In addition, social rehabilitation, reintegration into society and empowerment are the issues to be addressed to ensure compliance on the rights of the persons with disabilities.

\section{REFERENCES}

I. Murdoch G, Wilson AB Jr, eds. Amputation: Surgical Practice and Patient Management. St Louis, Mo: Butterworth-Heinemann Medical; 1996. DOI: 10.1002/bjs. 1800840360.

2. Eardley WG, Taylor DM, Parker P. Amputation and the assessment of limb viability: perceptions of two hundred and thirty two orthopaedic trainees. Ann R Coll Surg Engl 
20I0;92(5):4II-6. DOI: 10.1308/ $003588410 \times 12664192074973$.

3. Higgins TF, Klatt JB, Beals TC. Lower Extremity Assessment Project (LEAP)--the best available evidence on limb-threatening lower extremity trauma. Orthop Clin North Am 2010;4I(2):233-9. DOI: 10.1016/j.ocl.2009.12.006.

4. Esquenazi A, Yoo SK. Amputation Epidemiology and Assessment. American Academy of Physical Medicine and Rehabilitation. [Cited on: March 0I, 2019]. Available from URL: https://now.aapmr.org/lowerlimb-amputations-epidemiologyand-assessment/

5. Ziegler-Graham K, MacKenzie EJ, Ephraim PL, Travison TG, Brookmeyer R. Estimating the prevalence of limb loss in the United States: 2005 to 2050. Arch Phys Med Rehabil 2008;89(3):422-9. DOI: I0.1016/j.apmr.2007.II.005.

6. Masood J, Irfan A, Ghulam MK. Current Indications for major Lower Limb amputations at Civil Hospital Karachi. Pak J Surg 2008;24(4): 228-3I.

7. Rathore FA, Ayaz SB, Mansoor SN, Qureshi AR, Fahim M.
Demographics of Lower Limb Amputations in the Pakistan Military: A Single Center, ThreeYear Prospective Survey. Cureus $2016 \mathrm{Apr}$ II;8(4):e566. DOI: 10.7759/cureus.566.

8. Omoke NI, Nwigwe CG. Limb Amputations in Abakaliki, South East Nigeria. African J Med Health Sci 2016;5(I):30-5. DOI: 10.4103/ 2384-5589. 183890

9. Paudel B, Shrestha BK, Banskota AK. Two faces of major lower limb amputation. Kathmandu Univ Med J 2005;3(3):2I 2-6.

10. Pooja GD, Sangeeta L. Prevalence and aetiology of amputation in Kolkata, India: A retrospective analysis. Hong Kong Physiother J 20I3;3I(I):36-40. DOI: 10.1016/ j.hkpj.2012.12.002.

II. Rouhani A, Mohajerzadeh S. An Epidemiological and Etiological Report on Lower Extremity Amputation in Northwest of Iran. Arch Bone Jt Surg 20 I 3; I (2): I03-6.

12. Singh G, Pithawa AK, Ravindranath G. Study of Disabled Treated at Artificial Limb Centre. Med J Armed Forces India 2009 Jul; 65(3):232-4.
13. Maqsood M, Ali N, Bhat A, Bangroo FA, Dhanda MS, Singh R. Current trends of major lower limb amputations at a tertiary care centre of Jammu, India. Int J Med Sci Res Pract 20I 5 Jun 30;2(2):77-80.

14. Awais SM, Dar UZ, Saeed A. Amputations of limbs during the 2005 earthquake in Pakistan: a firsthand experience of the author. Int Orthop 2012 Nov;36(II):2323-6. DOI: I0. I007/s00264-0I2-I589-3.

15. Humail SM, Ilyas S, Baqai FU. Diabetic Foot: major cause of lower limb amputations. J Surg Pak 2004;9(4):|9-2|.

16. Salahuddin O, Azhar M, Imtiaz A, Latif M. A developing world experience with distal foot amputations for diabetic limb salvage. Diabet Foot Ankle 2013 Oct 21;4:22477. DOI: 10.3402/ dfa.v4i0.22477.

17. Unnikrishnan EP, Rollands R, Parambil SM. Epidemiology of major limb amputations: a cross sectional study from a South Indian tertiary care hospital. Int Surg J 20।7;4(5): I642-6. DOI: I0.18203/2349-2902.isj20I71613

\section{AUTHORS' CONTRIBUTIONS}

Following authors have made substantial contributions to the manuscript as under:

AA: Concept \& study design, acquisition of data, drafting the manuscript, final approval of the version to be published.

OA: Acquisition \& analysis of data, drafting the manuscript, final approval of the version to be published.

NA, TR, MG: Acquisition of data, critical review, final approval of the version to be published.

Authors agree to be accountable for all aspects of the work in ensuring that questions related to the accuracy or integrity of any part of the work are appropriately investigated and resolved.

CONFLICT OF INTEREST
Authors declared no conflict of interest
GRANT SUPPORT AND FINANCIAL DISCLOSURE
NIL

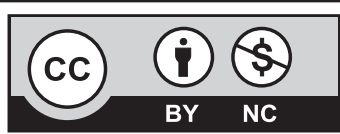

This is an Open Access article distributed under the terms of the Creative Commons Attribution-Non Commercial 2.0 Generic License. 